BARRETO. Paloma Dottori de Sá Como o pensamento freiriano pode contribuir no processo de empoderamento educacional quilombola na resistência de suas comunidades e culturas Dignidade Re-Vista, v.7, n.12, jul 2021

\title{
Como o pensamento freiriano pode contribuir no processo de empoderamento educacional quilombola na resistência de suas comunidades e culturas
}

How Freirean thought can contribute to the process of quilombola educational empowerment in the resistance of their communities and cultures.

\section{Paloma Dottori de Sá Barreto}

dottori.kejzelman@gmail.com

Graduanda em Relações Internacionais pela PUC Rio

\begin{abstract}
Resumo
Neste artigo, o objetivo é apresentar a contribuição do pensamento de Paulo Freire, no sentido de problematizar em que medida a educação escolar dialoga com as especificidades étnicoculturais das comunidades quilombolas e de que modo tais processos podem levar ao fortalecimento de seus territórios identitários. O artigo é embasado a partir de um estudo de caso na comunidade quilombola de Sobara.

Palavras-chave: Paulo Freire; educação popular; educação quilombola; Sobara.
\end{abstract}

\begin{abstract}
In this article, the objective is to present the contribution of Paulo Freire's thought, in the sense of problematizing to what extent school education dialogues with the ethnic-cultural specificities of quilombola communities and how these processes can lead to the strengthening of their identity territories. The article is based on a case study in the quilombola community of Sobara.
\end{abstract}

Keywords: Paulo Freire; popular education; quilombola education; Sobara. 
BARRETO. Paloma Dottori de Sá Como o pensamento freiriano pode contribuir no processo de empoderamento educacional quilombola na resistência de suas comunidades e culturas Dignidade Re-Vista, v.7, n.12, jul 2021

\section{DIGNIDADE}

\section{Introdução}

Ao fazermos uma análise das relações étnico-raciais e a temática educacional em comunidade remanescente de quilombo devemos, primeiramente, refletir sobre o papel dos afrodescendentes na história brasileira e levar em consideração temas como: escravidão, colonialidade, desigualdade, identidade, patrimônio imaterial, racismo, ancestralidade, cultura, resistência e quilombismo.

No livro O quilombismo (1980), Abdias do Nascimento explorou caracterizar o histórico do que é quilombo. Para Nascimento, os diferentes movimentos sociais de resistência física e cultural da população negra ganharam forma não só de grupos fugidos para o interior das matas na época da escravidão, e têm, também, um sentido bastante ampliado no âmbito político-social e na construção de identidade quilombola.

A partir de uma narrativa cronológica, iremos nos deparar com as consequências da diáspora africana, cuja violência se tornou prática comum para consolidação das estruturas hierárquicas vigentes até os dias atuais. Dito isto, deve-se problematizar e analisar as consequências desse sistema colonialista que edificou as bases de controle social, econômico e político. Que foi implicado num padrão de dominação e exploração, que envolveu o controle dos recursos naturais, dos modos produtivos e da exploração do trabalho de sujeitos que foram subalternizados.

Em primeiro lugar, faremos uma breve contextualização histórica e refletiremos sobre a ordem social, a resistência negra e o enfrentamento das formas explícitas e implícitas de racismo sofrido pela população negra. Em seguida, situaremos o debate sobre a necessidade de uma mudança e desenvolvimento dos processos educacionais, um projeto epistemológico decolonial que ressalta a necessidade transdisciplinar como construção alternativa à educação eurocêntrica.

O artigo apresentado aqui é o resultado de um estudo de caso sobre a Comunidade Remanescente de Quilombo Sobara, com destaque para a análise do contexto local com características etnográficas. $\mathrm{O}$ foco principal foi compreender as políticas públicas de Educação das Relações Étnico-Raciais e perceber a contribuição do pensamento freiriano para uma educação popular mesclada a uma educação quilombola.

\section{Um breve contexto local da Comunidade Remanescente de Quilombo Sobara}

A comunidade de Sobara é localizada no município de Araruama, no estado do Rio de Janeiro. Conhecido como sendo o "sertão" da região, deve-se percorrer cerca de 18 km em 
BARRETO. Paloma Dottori de Sá Como o pensamento freiriano pode contribuir no processo de empoderamento educacional quilombola na resistência de suas comunidades e culturas Dignidade Re-Vista, v.7, n.12, jul 2021

estrada de chão para chegar lá, partindo de um dos distritos do município chamado de São Vicente de Paulo. A paisagem rural é composta por pastos, canaviais e plantações de laranja. O acesso à comunidade é difícil, seja nos dias de chuva, pela condição das vias, seja pelos horários restritos do transporte público. O número de habitantes varia de acordo com a fonte, no último censo de Estudos Socioeconômicos dos Municípios do Estado do Rio de Janeiro feito pelo TCERJ em 2016 havia cerca de 130 famílias no quilombo.

A história da Comunidade Quilombola de Sobara é revivida a partir dos mais velhos e são os relatos sinceros do passado que fazem com que a história continue e possa ser revivida e reconstruída até os dias de hoje. Antigamente, eles diziam que os pais trabalhavam na lavoura e eram filhos de escravizados, ressaltavam que nasceram na Fazenda Espírito Santo ou no Sítio Benfica, local onde há ruínas de senzalas. Diz-se que muitos ex-escravizados herdaram pedaços de terra na região e que existia uma forte agricultura de subsistência local. A partir da década de 1970, grande parte foi desmatada para dar espaço aos pastos e à cana de açúcar.

Sobara possui apenas uma escola municipal de ensino fundamental, que vai somente até o quinto ano, chamada de Pastor Alcebíades Ferreira de Mendonça. A escola aparece no Censo Escolar como instituição de ensino na área quilombola somente em 2006, e tem trabalhado com um currículo diferenciado, a partir de temas da cultura afro-brasileira. Há uma alta taxa de abandono escolar na comunidade - muitos desistem por causa dos inúmeros obstáculos enfrentados, pois para dar continuidade aos estudos os alunos precisam se deslocar para a zona urbana. Isso significa que os estudantes devem se deslocar diariamente e necessitam de um transporte adequado. Outro fator importante da evasão escolar tem relação com o conhecimento presente na perspectiva curricular.

As informações disponibilizadas pela Fundação Cultural Palmares mostram que a comunidade de Sobara passou pelo processo de titularização da posse de terra e obteve a certidão RTID, que aborda informações cartográficas, fundiárias, agronômicas, ecológicas, geográficas, socioeconômicas, históricas e antropológicas, obtidas em campo e junto a instituições públicas e privadas, composta pelas seguintes peças: relatório antropológico; planta e memorial descritivo do perímetro do território. Isto significa, que passaram a fazer parte do Cadastro Geral de Remanescentes de Comunidades de Quilombos da FCP pela Portaria n. 104 de 20 de maio de 2016 (Palmares, 2017).

Foi registrado o depoimento, em uma reunião da associação de moradores, que o acesso à educação é um dos principais problemas, visto que a comunidade possui alto índice de analfabetismo funcional. De alguma maneira, os moradores sentem-se excluídos e esquecidos pelas autoridades do estado e do País, e deixam transparecer que a escolarização, como também 
BARRETO. Paloma Dottori de Sá Como o pensamento freiriano pode contribuir no processo de empoderamento educacional quilombola na resistência de suas comunidades e culturas Dignidade Re-Vista, v.7, n.12, jul 2021

o acesso ao ensino secundário e superior na região, são algumas das possibilidades para desenvolvimento de Sobara. No entanto, a realidade é que muitos jovens começam a trabalhar cedo e optam, muitas vezes por falta de alternativa, por trabalhos pesados, como mão-de-obra na colheita do canavial e outros afazeres em fazendas vizinhas.

De acordo com o estudo da autora Ana Carolina Batista, compreende-se a importância do tema da identidade para Sobara, já que os sujeitos desse espaço vêm tentando se ressignificar, buscando se organizar e reivindicar seus direitos.

Conforme Paulo Freire fala, sobre a necessidade de potencializar as possibilidades de desenvolver mecanismos educativos para emancipação, a compreensão crítica do ato de ler não se esgota na decodificação pura da palavra escrita ou da linguagem escrita, mas se antecipa e se alonga na inteligência do mundo (Freire, 2006, p.11).

A Educação Popular fundamenta a cultura como processo histórico, propondo uma educação capaz de compreender que os sujeitos são parte de uma história criada a partir de seu contexto histórico e social. É importante refletirmos que a modalidade da educação quilombola está inserida no contexto mais amplo de buscas para garantir espaços institucionais da educação formal tendo em vista a superação da posição subalterna da população negra na sociedade brasileira. É necessário que a educação seja de fato uma ferramenta que transforme os estudantes em sujeitos de sua história, e que assim se tornem agentes conscientes que possam questionar, compreender e refletir sobre seu mundo. Como Freire refletiu

O homem [mulher] não pode participar ativamente na história, se não é auxiliado a tomar consciência da realidade e de sua própria capacidade para transformá-la, pois ninguém luta contra as forças que não compreende. A realidade não pode ser modificada, senão quando o homem [mulher] descobre que é modificável e que ele pode fazê-lo. (FREIRE,1980, p.40)

Na E. M. Pastor Alcebíades Ferreira de Mendonça existem inúmeras formas de resistência e interculturalidade, como exemplo podemos citar as festas de comemoração do passado histórico e das lutas do movimento negro, buscando reforçar na comunidade o valor substancial do seu passado. Há vários projetos, como o "Batuque Reciclado", em que através da música se mantém vivas as raízes africanas em apresentações nas datas festivas da cidade de Araruama. Dele fazem parte 65 crianças que vestem túnicas e turbantes coloridos e tocam ritmos africanos com instrumentos construídos por elas a partir de materiais descartados. Além desse, há também o projeto do Mestre Cavalo, chamado de Grupo Independente de Capoeira de Araruama (Gicap) 


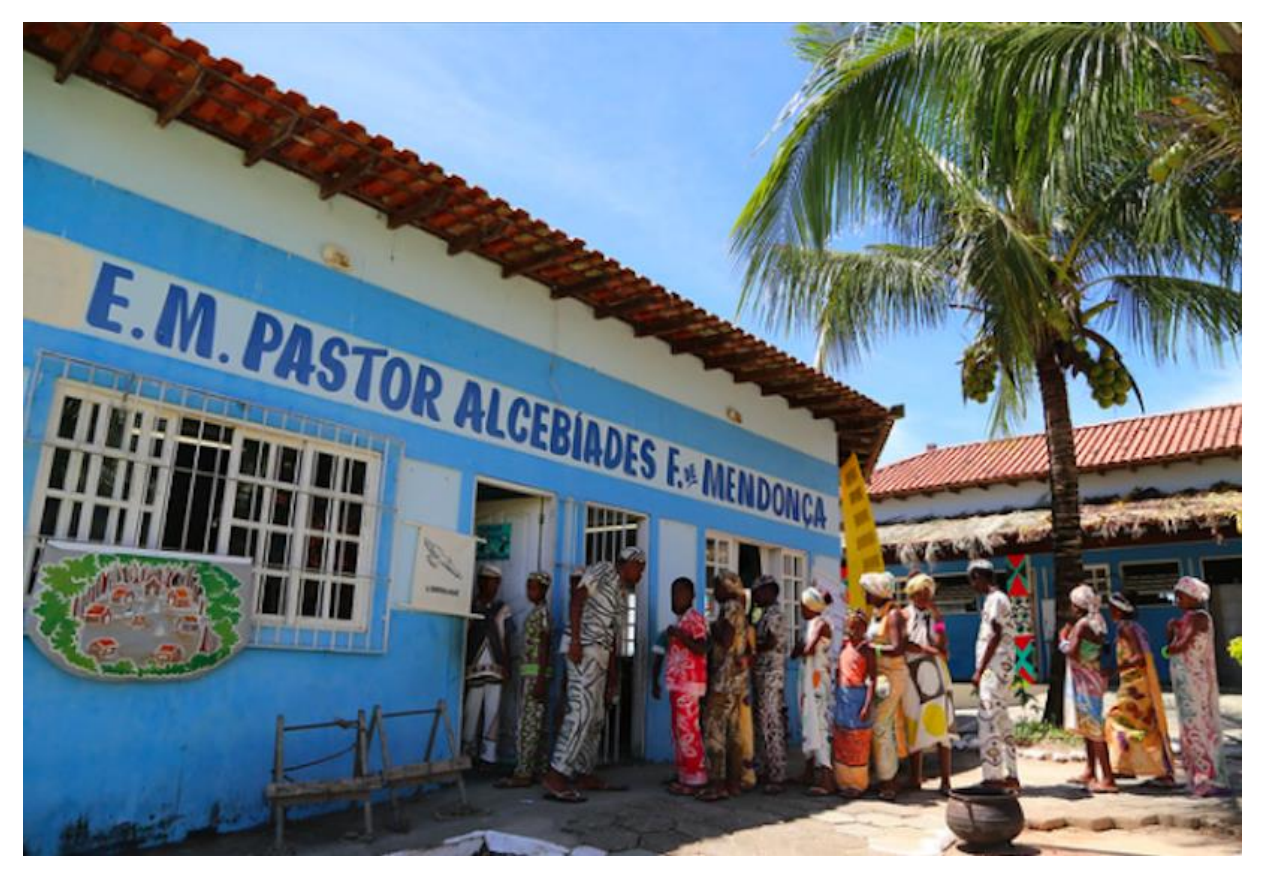

Figura 1. de Pastor Alcebíades Ferreira de Mendonça Fonte: Acervo Pessoal

Os exemplos de atividades em Sobara, mostram como as leis 10.639/2003 e 11.645/2008 foram uma conquista do movimento negro e são fundamentais para determinação da história da África-brasileira no ensino. A partir disto, devemos pensar na construção de um currículo embasado nos sujeitos para transformar suas realidades e que se aprofundem na compreensão e interpretação de suas próprias experiências e histórias.

A partir dos aprontamentos expressos, foi percebido que os currículos escolares das comunidades deveriam ter destacado as suas especificidades cultuais, que incorporasse as vozes, as experiências e histórias dos afrodescendentes e das relações étnicos-raciais. Assim, partimos da perspectiva freiriana de que a transformação social não se dá sem levar em consideração a importância da escola e com a convicção de que ensinar e aprender são processos indissociáveis.

\section{Da reflexão à problematização das práticas educacionais}

O Brasil, como a maioria dos países latino-americanos, é marcado pelo negacionismo do seu passado histórico e das relações de poderes que o atravessam e, por consequência, pela desigualdade econômica e social.

Segundo a Coordenação Nacional de Articulação de Quilombos (CONAQ), dentro de uma perspectiva histórica, as principais bandeiras de luta das comunidades quilombolas no Brasil, são: as reivindicações pelo direito à terra e permanência nos territórios em que vivem, a 
BARRETO. Paloma Dottori de Sá Como o pensamento freiriano pode contribuir no processo de empoderamento educacional quilombola na resistência de suas comunidades e culturas Dignidade Re-Vista, v.7, n.12, jul 2021

manutenção dos conhecimentos tradicionais da memória e autonomia dos modos de produção econômica, a superação do racismo e o acesso à educação de qualidade.

Devemos refletir que educação nas comunidades quilombolas acontece de maneira integral por meio da experiência e é articulada junto ao território, natureza e cultura, garantindo que as tradições do povo sejam resguardadas e transmitidas de geração a geração. Nas escolas de ensino tradicionais, os jovens encontram aulas que pouco ou nada conversam com as realidades desses povos. Essa escola é pautada em referenciais curriculares padronizados, que ignoram e discriminam outros tipos de saberes.

Partindo de uma leitura de Beatriz Nascimento (1977), é possível argumentar que a sociedade é configurada por um racismo estrutural e que vivemos o mito da chamada "democracia racial", que impõe de forma desigual condições e acessos aos bens públicos para a população negra. Para Nascimento (1977, p.107), o termo oculto desconsidera a existência do preconceito racial criando-se um processo que desalinha a história vivenciada e contada. Isto ocorre como aspecto para aliviar certas tensões de poder entre as raças que fazem parte da sociedade. Verifica-se que esse sistema de amansamento foi exercido como uma roupagem para manifestar preconceitos existentes no âmbito social, político, econômico, educacional na sociedade brasileira.

A partir desta leitura, define-se uma história marcada por "quase quinhentos anos de resistência à dor, ao sofrimento físico e moral, à sensação de não existir" (Nascimento,1977, p.39). Nesse contexto, a colonialidade não só caracterizou antropologicamente os negros como sub-raça, como também, naturalizou as práticas existentes na sociedade baseadas em um tipo de darwinismo social, que legitimou o uso da força e da violência. Esta fardagem faz parte de um olhar binário e codificado das diferenças de forma empírica: opressor e oprimido/ dominadores e subalternizados/ branco e pretos etc.

Com base na colonialidade de poder houve uma disputa do método científico embasado por teorias europeias para legitimar o conhecimento europeu como superior. As formas eurocêntricas do conhecimento são tidas como verdade universal e promovem a repressão de outras formas de conhecimento, negando a produção de saberes dos povos tradicionais, tidos como primitivos e irracionais. A colonialidade do saber se traduz em epistemicídio, uma vez que a modernidade trata a ciência como uma forma hegemônica do saber - que não permite outros tipos de conhecimento com relação aos saberes constituídos. As relações entre o dominador e o dominado refletem o contexto social amplo, mesmo sob o aspecto pessoal, e supõem que os dominados assimilem os mitos culturais do dominador (Freire, 1980, p. 64). 
BARRETO. Paloma Dottori de Sá Como o pensamento freiriano pode contribuir no processo de empoderamento educacional quilombola na resistência de suas comunidades e culturas Dignidade Re-Vista, v.7, n.12, jul 2021

A perspectiva da diferença requer um olhar sobre enfoques epistemológicos e sobre as subjetividades dos subalternos e excluídos. Catherine Walsh (2005) reflete sobre os processos educacionais a partir de conceitos como: pensamento sobre o outro, decolonialidade e pensamento crítico de fronteira. Para Walsh, muitas políticas públicas educacionais na América Latina (incluindo o Brasil) vêm sendo utilizadas em termos da interculturalidade e do multiculturalismo como forma de incorporar as demandas e os discursos subalternizados pelo ocidente, mesmo que o padrão epistemológico eurocêntrico e colonial continue a ser hegemônico. Dentro dessa perspectiva, a autora propõe um projeto a partir da ideia de uma prática política contraposta à geopolítica hegemônica do conhecimento.

Neste sentido, o quilombo busca resistir e existir a fim de recuperar sua ancestralidade. Por vezes, o conhecimento eurocêntrico distorce a comunidade negra e os resume à escravidão, não mencionando a luta quilombola pelos seus direitos e por meio de suas práticas cotidianas e de seus saberes singulares.

Tendo em vista essa questão posta em debate, por meio do decreto n. 4.887 (2003) foi estabelecida a autodeterminação dos membros das comunidades tradicionais. No campo das políticas educacionais, foram instituídas legislações para respaldar a garantia da educação dos quilombolas e a valorização da diversidade cultural e étnica, por meio dos Parâmetros Curriculares Nacionais, mais especificamente com a Lei 10.639 (2003) e a Lei de Diretrizes e Bases da Educação Básica (LDB) que enfatiza:

\begin{abstract}
a necessidade de se construir um projeto político pedagógico (PPP) que dialogue com o contexto socioeconômico, cultural e ambiental das comunidades quilombolas; que garanta aos estudantes o direito de se apropriar dos conhecimentos tradicionais e das formas de produção social e cultural das comunidades e que promova a valorização, respeito e preservação da história e da cultura quilombola, ressaltando a importância da participação das comunidades neste processo de construção. (CNE, 2012)
\end{abstract}

Tal lei fez com que fosse obrigatório o ensino sobre História e Cultura Afro-brasileira nas escolas, a partir da Diretrizes Curriculares Nacionais para a Educação das Relações Étnicoraciais (2007). Consideramos de extrema importância essas conquistas institucionais, pois, dá voz a memórias que foram silenciadas, e é um processo de reconhecimento étnico-racial.

Dentro desse contexto, deve-se buscar uma educação que respeite a visão de mundo, os valores, a linguagem, a ancestralidade e a especificidade deste povo, ou seja, numa escola quilombola deve ser implementada uma proposta pedagógica baseada na sua etnicidade. Compreender a educação como um processo singular de constituição de identidade, de 
formação enquanto quilombo, é uma das vertentes necessárias para a quebra do paradigma da desigualdade e da violência cultural.

\section{Nova produção de saberes e uma nova disputa epistemológica}

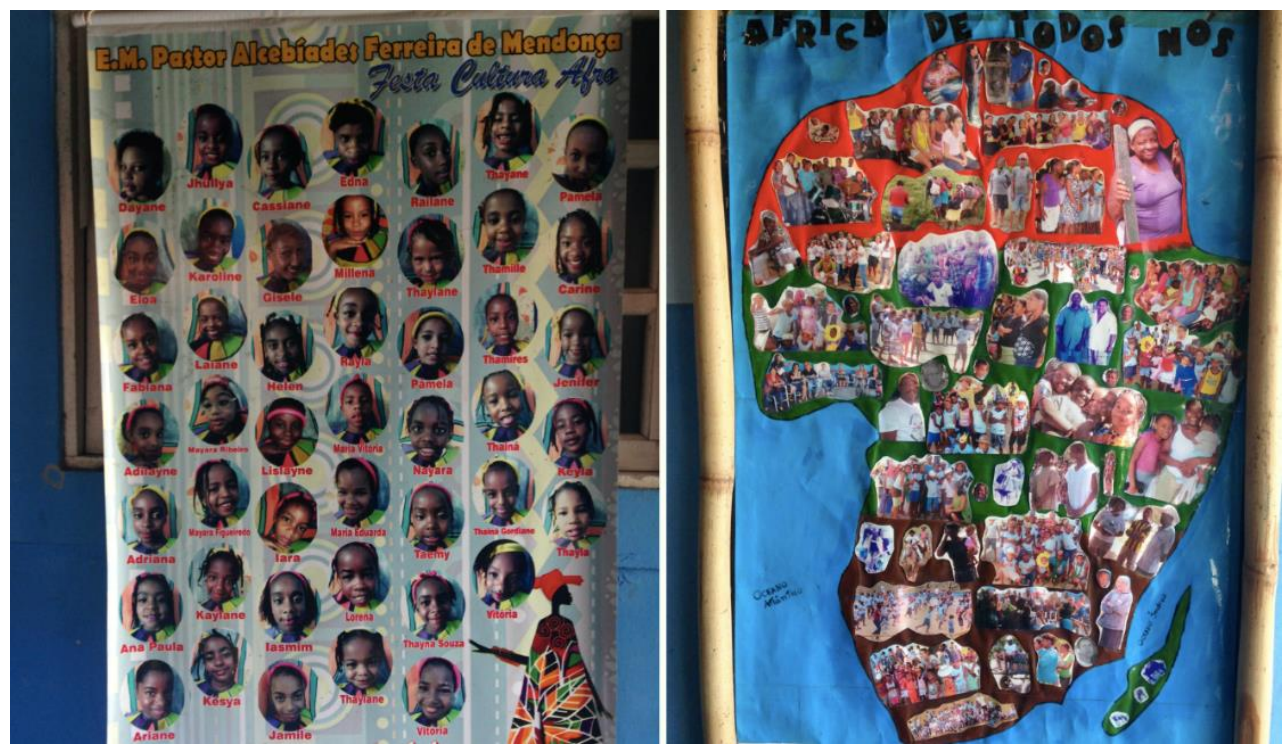

Figura 2. Mural de comemoração da cultura africana. Fonte: Acervo Pessoal

Segundo Freire (1980, p.57-58), ninguém melhor do que os oprimidos para compreender a realidade opressora. $\mathrm{O}$ autor diz que os oprimidos só conseguirão sua liberdade procurando-a em sua práxis e reconhecendo nela que é necessário lutar para consegui-la. De fato, a escola tem a oportunidade de contribuir para o fortalecimento ou (re)construção da identidade cultural dos alunos quilombolas e para a construção da cidadania.

A Educação é um processo de construção do conhecimento do ser humano, fruto das vivências em sociedade e não apenas nos limites da escola. É possível aprender com a comunidade com músicas populares, danças, comidas típicas, enfim, com os modos de ser e viver em sociedade, tanto quanto se aprende nas salas de aula. A formação escolar possibilita o entendimento de novos saberes, conforme Freire menciona:

quem forma, se forma e re-forma ao formar, e quem é formado forma-se e forma ao ser formado. [...] Não há docência sem discência, as duas se explicam e seus sujeitos, apesar de diferenças que os conotam, não se reduzem à condição de objeto um do outro. Quem ensina aprende a ensinar, e quem aprende, ensina ao aprender. (1996, p.25) 
BARRETO. Paloma Dottori de Sá Como o pensamento freiriano pode contribuir no processo de empoderamento educacional quilombola na resistência de suas comunidades e culturas Dignidade Re-Vista, v.7, n.12, jul 2021

Assim, deve-se fornecer benefícios teóricos epistemológicos para que os educandos pensem em suas ações cotidianas. Portanto, pensar o currículo nas escolas inseridas em comunidades quilombolas implica necessariamente selecionar seus elementos culturais. Faz sentido ter uma escola que incorpore em seu currículo a ancestralidade e a história da comunidade e do passado histórico das lutas e reivindicações do povo negro.

Faz-se necessário que existam professores e professoras que compreendam os sentidos dos elementos culturais para a vida das comunidades quilombolas para que, a partir daí, compreendam o papel da escola, do currículo, dos materiais didáticos utilizados e das atividades propostas em sala de aula para o fortalecimento da identidade sociocultural dos alunos.

\begin{abstract}
Ao exigir dele comportamento mecanizado pela repetição de um mesmo ato, com que realiza uma parte apenas da totalidade da obra, de que se desvincula, "domestica-o". Não exige atitude crítica total diante de sua produção. Desumaniza-o. Corta-lhe os horizontes com a estreiteza da especialização exagerada. Faz dele um ser passivo. Medroso. Ingênuo (...) A solução, na verdade, não pode estar na defesa de formas antiquadas e inadequadas ao mundo de hoje, mas na aceitação da realidade e na solução objetiva de seus problemas. (Freire, 2003, p. 42).
\end{abstract}

Os educadores devem refletir sobre os processos de ensinamento/aprendizagem, saindo do campo formal do conhecimento. A Educação Popular como campo de conhecimento, constituída pela defesa de uma educação humanizada e emancipadora, foi constituída a partir da literatura de Paulo Freire. O autor nos mostra outra forma de pensar o sujeito, a partir das vivências deste com o meio em que vive, partindo do princípio de que o povo produz o saber, sendo necessário valorizá-lo dentro dos processos de ensino e aprendizagem. Freire problematiza a passividade da educação formal e tradicional em prol de uma educação emancipadora, fundamentada no diálogo e na formação crítica do sujeito como ser pensante.

Por esse motivo, é necessário que haja um diálogo entre a educação popular proposta por Freire com as especificidades étnico-culturais das comunidades quilombolas e junto à lei 10.639/2003, para que ocorra a autoafirmação dos quilombolas enquanto sujeitos, conscientes de seu papel social a partir do processo identitário e de fortalecimento educacional.

\title{
Considerações finais
}

Freire pensa numa revolução pelo diálogo. Mas não qualquer diálogo, um diálogo onde os oprimidos tenham vozes e possam se articular, conhecer e reconhecer formas de luta contra opressão, se conscientizando desta para superá-la. 
BARRETO. Paloma Dottori de Sá Como o pensamento freiriano pode contribuir no processo de empoderamento educacional quilombola na resistência de suas

Por isso, a importância da criação de uma metodologia pedagógica participativa que objetiva a libertação dos sujeitos por meio da educação. Não falamos apenas de um pensamento racional, mas, sim, uma educação firmada na vivência, nos modos de se fazer e de agir. Nosso artigo relaciona a experiência da liberdade a partir do reconhecimento da ancestralidade e historicidade africana-brasileira. Percebemos que a proposta educacional de Freire é fazer com que os oprimidos, como categoria de classe e histórica, se libertem. Nesse aspecto, a educação é um direito fundamental, por isso é importante fortalecer as abordagens educativas que respeitem a interculturalidade e o pluralismo cultural brasileiro.

Atualmente, boa parte da implementação de políticas públicas sobre a questão quilombola no Brasil é pouco eficiente. Para a comunidade de Sobara, a maioria das políticas públicas nunca chegou, evidenciando o acesso desigual a bens e direitos para a população de comunidades tradicionais. Parte do problema tem origem histórica através da criação de uma estrutura fundiária que privilegia o latifúndio. Essas estruturas de desigualdade se acentuam em regiões rurais como a de Sobara. Tendo em vista esse panorama geral, acredita-se que o Estado deva promover políticas públicas de educação necessárias para que ocorra um protagonismo político e socioeconômico nas Comunidades Remanescentes de Quilombo.

Como Paulo Freire muito bem colocou em seu livro Pedagogia do Oprimido (1981), o papel da educação é um ato político que liberta os indivíduos por meio da consciência crítica, transformadora e diferencial, emergindo na educação como uma prática de liberdade.

Finalizamos destacando a metodologia da educadora popular Noelia Rodrigues Pereira Rego: transformar, formar e agir, aplicada a ações de enfrentamento como uma forma de continuar (Re)existindo e mantendo vivas as tradições e lutas das comunidades remanescentes de quilombo. 
BARRETO. Paloma Dottori de Sá Como o pensamento freiriano pode contribuir no processo de empoderamento educacional quilombola na resistência de suas comunidades e culturas Dignidade Re-Vista, v.7, n.12, jul 2021

\section{Referências bibliográficas}

BATISTA, Ana Carolina Mota. Relações étnico-raciais na voz do professor: os debates curriculares no contexto quilombola. Programa de Pós-Graduação em Ensino de História, Instituto de Ciências Humanas e Filosofia, Universidade Federal Fluminense, Niterói, 2016.

BRASIL. Ministério da Educação. Educação Quilombola Apresentação. Brasília, 2007.

BRASIL. Curriculares Nacionais para a Educação Escolar Quilombola. Parecer do Conselho Nacional de Educação / Câmara de Educação Básica (Ces/Cne), n ${ }^{\circ}$ 16/2012. Resolução no 8 de 20 de novembro de 2012. Diário Oficial da União, Brasília, 21 de novembro de 2012.

FREIRE, P. Pedagogia do Oprimido. 10.ed. Rio de Janeiro: Paz e Terra, 1981.

FREIRE, P. A importância do Ato de Ler: três artigos que se completam. 29.ed. São Paulo: Cortez, 1994.

FREIRE, P. Educação como prática de Liberdade. 26.ed. Rio de Janeiro: Paz e Terra, 2002.

FREIRE, P. Educação e Mudança. 24.ed. Rio de Janeiro: Paz e Terra, 2001.

FREIRE, P. Educação como prática da liberdade. 23.ed. Rio de Janeiro: Paz e Terra, 1999.

FREIRE, P. Pedagogia da autonomia: saberes necessários à prática educativa. São Paulo: Paz e Terra, 1996.

NASCIMENTO, Abdias. O Quilombismo. Petrópolis:Vozes, 1980.

NASCIMENTO, Beatriz. O Quilombo do Jabaquara. Revista de Cultura Vozes, 1979.

NASCIMENTO, Beatriz. Nossa democracia racial. Revista IstoÉ. Edição de 23 nov1977.

PALMARES. Certidões expedidas às comunidades remanescentes de quilombos (CRQs) atualizadas até a Portaria $\mathrm{n}^{\circ}-104 / 2016$, publicada no DOU de 20/05/2016. Disponível em: http://www.palmares.gov.br/wpcontent/uploads/2016/06/COMUNIDADESCERTIFICADAS.pdf. Acesso em: 12 set 2020.

QUILOMBO? Quem Somos Nós! Coordenação Nacional de Articulação de Quilombos CONAQ. Disponível em: http://conaq.org.br/quem-somos/ Acesso em: 4 nov 2020.

REGO, Noelia Pereira. Práticas Investigativas Transformadoras e a Educação Popular como perspectivas de Trans-form-AÇÃO. Revista Vozes dos Vales, n.14, Ano VII, out 2018

WALSH. Catherine. Interculturalidad crítica y (de) colonialidad: Ensayos desde Abya Yala. Quito: Ediciones Abya-yala, 2012. 